Derleme

H.Ü. Çocuk Gelişimi Lisans Programı

\title{
Bologna Çalışmaları Kapsamında Hacettepe Üniversitesi Çocuk Gelişimi Bölümü Lisans Programı Güncelleme Çalışmaları
}

\author{
Çiğdem Aytekin ${ }^{1}$, Burcu Bülbün Akt ${ }^{1}$ \\ ${ }^{1}$ Hacettepe Üniversitesi Sağlık Bilimleri Fakültesi Çocuk Gelişimi Bölümü
}

\begin{abstract}
Özet
Hacettepe Üniversitesi Çocuk Gelişimi Bölümü, 1968 yılında kurulmuş ve 1972 yılından itibaren mezun veren bir lisans programıdır. Bölüm, Sağlık Bilimleri Fakültesi bünyesinde eğitim-öğretim ve bilimsel faaliyetlerini sürdürmektedir. Köklü bir bölüm olan Hacettepe Üniversitesi Çocuk Gelişimi Bölümü, Ülkemizdeki ilk Çocuk Gelişimi Bölümü olmakla birlikte, uzun yıllar tek bölüm olarak faaliyet göstermiş ve birçok lisans mezunu vermiştir. Yıllar içerisinde alana yönelik gelişen ihtiyaçlar doğrultusunda, Çocuk Gelişimi Bölümü lisans ders programının güncellenmesine gereksinim duyulmuş, öğretim programı güncelleme çalışmalarına başlanmıştır. Başlatılan güncelleme çalışmaları, 2012 yılında Hacettepe Üniversitesi’nde başlatılan ve pilot fakülte olarak belirlenen Sağlık Bilimleri Fakültesinin Bologna çalışmaları kapsamında da ele alınmış ve bu kapsamda programa ilişkin gerekli düzenlemeler yapılmıştır. Çocuk Gelişimi Bölümü lisans programı güncelleme çalışmalarına, iç ve dış paydaşların görüşleri alınarak başlanmıştır. Paydaş görüşlerinin yanı sıra, yurt dışında benzer bölümlerin lisans programları incelenmiş, bu konuya yönelik gerekli araştırmalar yapılmıştır. Yapılan bu çalışmalar sonucunda, Çocuk Gelişimi Bölümü lisans ders programı, derslere yeni kod ve isimler verilerek yeniden oluşturulmuş ve Bologna Süreci ile uyumlaştırılmıştır. Hacettepe Üniversitesi Çocuk Gelişimi Bölümü lisans ders programı 2012-2013 öğretim yılından itibaren uygulanmaya başlamıştır. Zaman içerisinde uygulamalardaki gereksinimlere göre ders programıyla ilgili güncelleme çalışmaları yapılarak, program 2015 Nisan'da son halini almıştır.
\end{abstract}

Anahtar kelimeler: Hacettepe Üniversitesi, çocuk gelişimi bölümü, lisans programı, Bologna

Sorumlu Yazar: Çiğdem Aytekin, Hacettepe Üniversitesi, H.Ü. Sağlık Bilimleri Fakültesi Çocuk Gelişimi Bölümü D Blok 6. Kat 06100 - Ankara, 031230515 26, cgdmc@ hacettepe.edu.tr

Bu çalışma, 17-18 Eylül 2015 tarihleri arasında düzenlenen “I. Bologna Süreci Araştırmaları Kongresi”nde sözlü bildiri olarak sunulmuştur. 
Review Paper

Hacettepe University, Undergraduate Program for Development of Child Education

\title{
Update Studies Of Hacettepe University Department Of Child Development Bachelor Program As Part Of Bologna Process
}

\author{
Çiğdem Aytekin ${ }^{1}$, Burcu Bülbün Akt1 ${ }^{1}$ \\ ${ }^{1}$ Hacettepe Üniversitesi Sağlık Bilimleri Fakültesi Çocuk Gelişimi Bölümü
}

\begin{abstract}
Hacettepe University Department of Child Development is a bachelor degree program which was established in 1968 and has been graduated students since 1972. Department is carrying out educational and scientific activities at Faculty of Health Sciences. Hacettepe University Department of Child Development is the first Department of Child Development in Turkey. The department was the only Child Development Department for many years and graduated several students. Over the years, according to the changing needs of Child Development area, it was needed to review of bachelor program and a study was started to update the program. Update studies was handled within the scope of Bologna Process studies which started as a pilot study at Hacettepe University Faculty of Health Sciences in 2012 and essential regulation was made. Department of Child Development bachelor program update studies started with taking the views of internal and external partners. Besides partner's views, similar abroad bachelor programs were examined and essential researches were made. As a result of these studies, Child Development bachelor program was redesigned and adapted to Bologna Process with new lesson codes and names. Hacettepe University Department of Child Development new bachelor program was first applied at 2012-2013 educational year. Bachelor program was finalized at April 2015 after updates necessary updates according to the application of program.
\end{abstract}

Keywords: Early intervention, processes of early intervention, developmental support

Corresponding Author: Çiğdem Aytekin, Hacettepe Üniversitesi, H.Ü. Sağlık Bilimleri Fakültesi Çocuk Gelişimi Bölümü D Blok 6. Kat 06100 - Ankara, 0312305 15 26, cgdmc@ hacettepe.edu.tr This study, was presented as a verbal notice in the First Congress of Research on the Bologna Process which was conducted in 17th-18th of September, 2015. 


\section{Giriş}

Hacettepe Üniversitesi (H.Ü.) Çocuk Gelişimi Bölümü, 1968 yılında Çocuk Gelişimi ve Eğitimi adı ile kurulmuş köklü bir bölümdür. Bölüm, Bakanlar Kurulu'nun 21.05.2007tarih ve 2007/12216 sayılı kararı ile H.Ü. Sağlık Bilimleri Fakültesine bağlanarak Çocuk Gelişimi Bölümü adı ile faaliyetlerini sürdürmektedir (Hacettepe Üniversitesi Çocuk Gelişimi Bölümü, 2015; Doğan ve Baykoç, 2015).

H.Ü. Çocuk Gelişimi Bölümünün Sağlık Bilimleri Fakültesi bünyesinde yer almasıyla birlikte, lisans öğretim programında güncelleme çalışmalarına başlanmıştır. Bölüm mezunlarının sağlık, eğitim ve sosyal alanlarda daha donanımlı ve verimli çalışmalarını sağlayacak bilgi, beceri ve deneyimlerin kazandırılmasına yönelik yeni derslerin yer alması, var olan derslerin içeriğinin güncellenmesi gerektiği düşünülmüş ve bu kapsamda program güncelleme çalışmalarına odaklanılmıştır.

2012 yılında Hacettepe Üniversitesi bünyesinde başlayan Bologna Süreci çalışmaları kapsamında H.Ü. Çocuk Gelişimi Bölümünün bağlı olduğu Sağlık Bilimleri Fakültesi pilot fakülte olarak seçilmiş ve lisans programlarının Bologna hedefleriyle uyumlulaştırılması ihtiyacı ortaya çıkmıştır.

Bologna Süreci, 2010 yılına kadar Avrupa Yükseköğretim Alanı yaratmayı hedefleyen bir reform sürecini ifade etmektedir. Türkiye bu sürece 2001 yılında dahil olmuştur. Bologna Süreci yasal bir bağlayıcılık içermemekle birlikte, her ülkenin özgür iradeleriyle katıldıkları ve ülkelerin Bologna Süreci'nin öngördügü hedefleri kabul edip etmeme hakkına sahip oldukları bir oluşumdur. Yükseköğretim sistemlerinin kendilerine özgü farklılıklarının korunarak birbirleriyle karşılaştırılabilir olması ve uyumlu hale getirilmesi amaçlanmaktadır. Böylelikle, bir ülkeden ya da yükseköğretim sisteminden bir diğerine kolaylıkla geçiş sağlanması, öğrenciler ile öğretim görevlilerin hareketliliği ve istihdamının artırılması planlanmaktadır (Yükseköğretim Kurulu (YÖK), 2015a).

Bologna Süreci çalışmaları, Hacettepe Üniversitesi'nde Bilimsel Araştırma Projeleri Koordinasyon Birimi bünyesinde alt yapı projesi olarak, Mart-Ağustos 2012 tarihleri arasında başlamıştır. Çalışmalar iki aşamalı olarak planlanmış olup, ilk aşama Sağlık Bilimleri Fakültesi, Eğitim Fakültesi ve Polatlı Teknik Bilimler Meslek Yüksekokulu olmak üzere üç akademik birim bünyesinde gerçekleşmiştir. İkinci aşama çalışmalar ise tüm akademik birimlerin dahil edilmesi ile 2012 Eylül ayında gerçekleştirilmiştir. Güncellenen tüm akademik programlar 19 Mart 2014 tarihli Üniversite Senatosu kararı ile onaylanmıştır (Hacettepe Üniversitesi, 2015a). 
H.Ü. Çocuk Gelişimi Bölümü lisans programı güncelleme çalışmaları, Sağlık Bilimleri Fakültesi bünyesinde başlayan Bologna Süreci çalışmaları ile devam etmiş, gerekli güncelleme ve uyumlaştırma çalışmaları bu kapsamda tamamlanmıştır.

H.Ü. Çocuk Gelişimi Bölümü lisans programı güncelleme çalışmaları kapsamında, öncelikle iç ve dış paydaşların görüşlerine ihtiyaç duyulmuştur. Bu amaçla, gerek yüz yüze görüşmeler gerekse yazılı olarak paydaş görüşleri alınmıştır. İç paydaş olarak son sınıf öğrencilerinin ve bölüm öğretim üyelerinin/elemanlarının, öğretim programıyla ilgili gereksinimleri, alınan derslerin dönemleriyle ilgili görüşleri, lisans programında kapsamının genişletilmesini istedikleri konular, staj içerikleri gibi konularda görüşlerine başvurulmuştur. Dış paydaşlar olarak ise, farklı resmi ve özel kurumlarda çalışan bölüm mezunlarının görüşleri alınmıştır. Bu kapsamda, Milli Eğitim Bakanlığı, Aile ve Sosyal Politikalar Bakanlığı, Sağlık Bakanlığı ve Adalet Bakanlığı bünyesinde hem Bakanlık birimlerinde hem bu Bakanlıklara bağlı diğer kurumlarda (hastaneler, kreşler, özel eğitim merkezleri, rehberlik araştırma merkezleri, çocuk mahkemeleri, çocuk yuvaları-yetiştirme yurtları, vb.) çalışanlar ile alanla ilgili dernek ve vakıflarda çalışan bölüm mezunlarının alana ilişkin gereksinimlerini göz önünde bulundurarak öğretim programı güncelleme çalışmalarına ilişkin görüşlerini belirtmeleri istenmiştir.

Paydaş görüşlerinin yanı sıra, yurt dışında bulunan eşdeğer bölümlerin lisans programları incelenmiş, bu konuya yönelik gerekli inceleme ve araştırmalar yapılmıştır. $\mathrm{Bu}$ programlarda yer alan dersler içerikleri ve kredileri açısından değerlendirilmiş ve oluşturulan dersler havuzunda toplanmıştır.

Bölüm lisans programı güncelleme çalışmaları, 2012 yılında Hacettepe Üniversitesi bünyesinde, seçilen pilot fakültelerde başlatılan Bologna Süreci çalışmaları kapsamında (Hacettepe Üniversitesi, 2015a) devam etmiştir. Bologna Süreci çalışmaları kapsamında, Çocuk Gelişimi Bölümü Bologna ekibi oluşturulmuş ve bu ekip H.Ü. bünyesinde düzenlenen Bologna Eğitim Toplantılarına katılarak çalışmaların nasıl yürütülmesi gerektiği konusunda bilgi edinmiştir.

Tüm bu çalışmalar kapsamında, Çocuk Gelişimi Bölümü Bologna ekibi ve bölüm öğretim üye ve görevlileri işbirliğinde, paydaşlardan alınan görüşler değerlendirilmiş; hizmet verilen kitlenin ve mezunların gereksinimlerini en iyi şekilde karşılayabilecek ve bir Çocuk Gelişimci olarak yeterli donanıma sahip meslek elemanları yetiştirmeyi hedefleyen bir lisans programı oluşturulması hedeflenmiştir. Bu bakış açısıyla, daha önceden oluşturulan dersler havuzu gözden geçirilerek uygun görülen dersler belirlenmiştir. Programa aktarılan her bir ders Bölüm Akademik Kurul'unda tek tek ele alınarak değerlendirilmiş ve derslerin kur 
tanımları yapılmıştır. Yapılan tüm çalışmalar Bologna hedefleriyle örtüşecek ve bu sürece ilişkin yapılması gereken çalışmaları kapsayacak şekilde yürütülmüştür. Program kapsamında yer alan derslere yeni kod (ÇGL) ve isimler verilerek H.Ü. Çocuk Gelişimi Bölümü lisans ders programı güncellenmiştir.

Lisans programı güncelleme ve Bologna Süreci çalışmaları kapsamında, öncelikle Bölüm Bologna Kılavuzu hazırlanmıştır. Kılavuzda; program hakkında genel bilgi, kazanılan derece, kazanılan derecenin düzeyi, kayıt kabul şartları, kazanılan derece gereklilikleri ve kurallar, önceki öğrenmenin tanınması, program tanımı, program yeterlilikleri, temel alan yeterlikleri-program yeterlilikleri matrisi, ders-program yeterlilikleri matrisi, mezunları mesleki profili, bir üst dereceye geçiş, program yapısı, öğretim programı, sınavlardeğerlendirme ve notlandırma, mezuniyet koşulları, eğitim türü, bölüm başkanına ilişkin bilgiler yer almaktadır (Hacettepe Üniversitesi, 2015b).

Bologna Süreci kapsamında Yükseköğretim Kurulu Başkanlığı'nın internet sayfasında yer alan yönergeler doğrultusunda, Türkiye Yükseköğretim Yeterlilikler Çerçevesi (TYYÇ) 6. Düzey (Lisans Eğitimi) Yeterlilikleri (YÖK, 2015b) çerçevesinde 15 tane program öğrenme çıktısı/program yeterlilikleri belirlenmiştir. Belirlenen "Program Yeterlilikleri" ile "Türkiye Yükseköğretim Yeterlilikler Çerçevesi (6. Düzey, Lisans Eğitimi) Sağlık Temel Alanı Yeterlilikleri" matrisi oluşturulmuştur. Ayrıca, "Ders" ile "Program Yeterlilikleri" matrisi hazırlanarak Bölüm Bologna Kılavuzunda yer almıştır (Hacettepe Üniversitesi, 2015b).

H.Ü. Çocuk Gelişimi Bölümü Lisans Programında yer alan her bir dersin "Ders Bilgi Paketleri” üzerinde çalışılmıştır. Her bir dersin ders sorumlusu, ders bilgi paketleri doğrultusunda ilgili dersin amacını, öğrenme çıktılarını, ders içeriğini, kaynakları, haftalık ders konularını, dersin değerlendirme sistemini, öğrenci iş yükü tablosunu ve dersin öğrenme çıktıları ile program yeterlilikleri arasındaki ilişki tablosunu hazırlamıştır (Hacettepe Üniversitesi, 2015b).

Çalışmalar kapsamında, 2012 öncesi girişli öğrencilerin almış oldukları program ile güncellenen programın bir karşılaştırılması yapılmış, birbirine eşdeğer tutulacak dersler belirlenmiş ve "Ders Eşdeğerlikleri Tablosu” oluşturulmuştur. 2012 öncesi girişli veya af kanunundan yararlanarak geri dönen öğrencilerin başarısız oldukları derslerinin yerine alacakları yeni derslerin belirlenmesinde bu tablodan yararlanılmaktadır. Ayrıca, programdan kaldırılan derslere ilişkin olarak da "Programdan Kaldırılan Dersler Tablosu” oluşturulmuştur. $\mathrm{Bu}$ kapsamda öğrencilerin programındaki değişiklikler danışmanlar tarafından değerlendirilmiş ve programdan kaldırılan derslerden başarısız olan öğrencilerin üzerinden bu 
dersler silinerek yerine alacakları yeni dersler ile başarısız olunan dersin eşdeğeri varsa öğrencinin alacağı eşdeğer dersler belirlenmiştir.

Bologna Süreci çalışmaları doğrultusunda uyumlaştırılan lisans programlarında öğrencilerin mezun olabilmesi için 240 AKTS (Avrupa Kredi Transfer ve Biriktirme Sistemi) ders kredisi toplaması gerekmektedir (YÖK, 2015c). 240 AKTS kredisinin en az \%25'inin seçmeli derslerden alınması gerekir (Hacettepe Üniversitesi, 2015c). AKTS bir dersin ya da diploma programının belirlenen öğrenme çıktıları ile yeterliliklere dayalı hedeflerinin başarılabilmesi için gerekli iş yükünü göz önünde bulundurarak yapılan kredi sistemi hesaplamasını ifade etmektedir. AKTS kredisi, öğrencinin bir dersi başarıyla tamamlaması için yapması gereken bütün çalışmaları (örneğin, teorik ders, uygulama, ödevler, sınavlar, seminer, bireysel çalışmalar gibi) kapsayan ve iş yükünü temel alan bir değerdir (YÖK, 2015c). Dolayısıyla, Bologna Süreci kapsamında, öğrencilerin H.Ü. Çocuk Gelişimi Lisans Programından mezun olabilmeleri için toplamda 240 AKTS kredisi kazanması gerekmektedir.

H.Ü. Çocuk Gelişimi Bölümü Lisans ders programında, öğrenciler bu toplam kredinin 180 AKTS'sini programda yer alan zorunlu derslerden, 60 AKTS'sini ise seçmeli derslerden tamamlamak durumundadır. Lisans ders programında öğrencilerin alabilecekleri 31 tane seçmeli ders bulunmaktadır ve her bir seçmeli dersin AKTS kredisi farklıdır. Öğrenciler lisans programında yer alan 31 seçmeli dersin yanı sıra, üniversitenin diğer bölümlerinin açtığı ve almalarına onay verilen dersleri de alarak toplam AKTS kredisini tamamlayabilmektedirler. H.Ü. Çocuk Gelişimi Lisans Ders Programında yer alan seçmeli derslerin toplam AKTS kredisi 85'tir.

Hacettepe Üniversitesi 2012 yılı Bologna Süreci çalışmaları kapsamında güncellenen Çocuk Gelişimi Lisans Ders Programı, ortak zorunlu dersler dahil olmak üzere 60 zorunlu (180 AKTS), 31 seçmeli olmak üzere toplamda 91 dersten oluşmuştur. Ayrıca, programda tüm H.Ü. öğrencilerinin alabileceği 7 tane alan içi seçmeli ders (21 AKTS) yer almıştır. Programda öğrencilerin zorunlu olarak farklı dönemlerde almaları gereken toplamda 9 uygulama dersi yer almaktadır. Lisans ders programında ikinci yılda 1 adet, üçüncü yılda 2 adet, dördüncü yılda ise birisi üçüncü sınıf yaz döneminde olmak üzere 6 adet uygulama dersi yer almıştır. Çocuk Gelişimi Bölümü Öğrencileri, çocuk gelişimi ile ilgili farklı alanlarda uygulama/staj yapma olasıllğına sahiptir; örneğin, topluma hizmet uygulamaları kapsamında farklı dernek, vakıf ve özel kuruluşlarda; özel eğitim ve rehabilitasyon merkezleri ile rehberlik araştırma merkezlerinde; bebeklik ve erken çocukluk dönemi çocuklara hizmet veren kreş, anaokulu ve anasınıflarında; hastaneler, aile sağlı̆̆ merkezleri, toplum sağlığı merkezleri gibi sağlık kuruluşlarında; korunmaya muhtaç çocuklara hizmet veren kamu kuruluşlarında ve 
çocukla ilgili hizmet veren diğer özel ve kamu kuruluşlarında uygulama yapma firsatı bulmaktadır. H.Ü. Çocuk Gelişimi Lisans Ders Programında bazı teorik ve uygulamaları derslerin ön koşulları belirlenmiştir, öğrenciler bu ön koşulları yerine getirmeden ilgili dersi alamamaktadır. Ayrıca, programda 2 adet eşzamanlı ders yer almaktadır, öğrenciler eşzamanlı dersleri birlikte almalı veya eşzamanlı alınması gereken öncelikli dersi daha önceki dönemlerde alıp başarmış olmalıdır.

H.Ü. Bologna Süreci çalışmaları kapsamında pilot fakülte olarak belirlenen Sağlık Bilimleri Fakültesi bünyesinde Çocuk Gelişimi Bölümü, Lisans Ders Programı güncelleme çalışmalarını 2012 yılı Temmuz ayında tamamlamıştır. Güncellenen ders programı, 01.08.2012 tarih ve 258 sayılı H.Ü. Senatosunun kararı ile 2012-2013 Güz Döneminden itibaren uygulamaya konulmuştur (Hacettepe Üniversitesi, 2012).

Yeni lisans ders programının uygulamaya konulmasıyla birlikte, yeni ders programı ve Bologna Süreci ile ilgili olarak öğrencilerin uyum sürecine ilişkin gerekli çalışmalar planlanmış ve uygulanmıştır. Bu kapsamda, Çocuk Gelişimi Bölümü Lisans Koordinatörlüğü ve Bologna ekibi tarafından lisans öğrencileriyle büyük bir toplantı organize edilmiştir. $\mathrm{Bu}$ toplantıda öğrencilere AKTS ile ilgili bilgilendirme yapılmış, yeni ders programı ve dikkat etmeleri gereken diğer tüm hususlar ayrıntılı olarak anlatılmıştır. Ayrıca, her türlü sorularında danışmanları tarafından belirlenen saatlerde danışmanları ve Bölüm Lisans Koordinatörlüğü ile görüşebilecekleri belirtilmiştir. Buna ek olarak, bölümün internet sayfasında her dönem için öğrencilerin program kayıtlarında dikkat etmeleri gereken hususlar ayrıntılı bir şekilde yayınlanmıştır. Güncelleme çalışmalarıyla ilgili, öğrencilerin bilgilendirilmelerinin yanı sıra öğrenci danışmanlarına da ayrıntılı bir bilgilendirme yapılmış, süreçle ilgili olarak öğrencilerin kayıtlarında yararlanacakları bir dosya hazırlanarak tüm danışmanlara verilmiştir. Bölüm Lisans Koordinatörlüğü ve Öğretim Üyeleri, 2012 öncesi girişli öğrencilerin sınıflara göre almaları gereken zorunlu dersleri belirleyerek öğrenci danışmanlarına bilgilendirme yapmış olup, danışmanlar 2012 öncesi girişli öğrencilerin programlarının yeni programla uyumlaştırılması ile ilgili olarak ders kayıt dönemi başlamadan önce gerekli çalışmalarını tamamlamışlardır (eşdeğer derslerin belirlenmesi, kaldırılan derslere ilişkin öğrencilerin durumuna göre gerekli işlemlerin belirlenmesi, vb.).

Güncellenen H.Ü. Çocuk Gelişimi Lisans Ders Programı, 2012-2013 Güz döneminde uygulanmıştır. Uygulandığı döneminin sonunda, ders sorumluları ve bölüm öğrencilerinden alınan geri bildirimler sonucunda, programdaki bazı derslerle ilgili dönem, kredi, isim değişiklikleri ile içerik düzenlemesi yapma gerekliliği ortaya çıkmıştır. Bu doğrultuda, farklı dönemlerde gerekli çalışmalar yapılarak ilgili dosyalar değerlendirilmek üzere H.Ü. Eğitim 
Komisyonuna sunulmuştur. Son olarak, gereksinimler doğrultusunda 22.04.2015 tarih ve 160 sayılı H.Ü. Senatosu kararıyla Çocuk Gelişimi Lisans Ders Programı 2015-2016 Güz döneminde uygulanan son halini almıştır. Yapılan son değişiklik ile H.Ü. Çocuk Gelişimi Lisans Ders Programında 59 zorunlu, 37 seçmeli ders; 8 zorunlu uygulama dersi yer almaktadır. Uygulama derslerinden ikisi birleştirilerek tek bir dönemde tüm günlük bir uygulama dersi olarak programda yer almaktadır. Seçmeli derslerin AKTS toplamı ise 113'e yükselmiştir (Hacettepe Üniversitesi, 2015b).

\section{Sonuç}

Sonuç olarak, Çocuk Gelişimi Bölümü Lisans Ders Programı H.Ü.'de 2012 yılında başlayan Bologna Süreci çalışmalarıyla birlikte, pilot fakülte olarak seçilen Sağlık Bilimleri Fakültesi bünyesinde gerçekleşen çalışmalar kapsamında güncelleştirilmiştir. 2012 Temmuz ayında güncelleme çalışmaları tamamlanan lisans ders programı 2012-2013 Öğretim yılı başında uygulamaya konulmuş, eski programla yeni programın uyumlaştırılmasına yönelik gerekli çalışmalar yapılarak öğrenciler program kayıtlarını gerçekleştirmiştir. Güncellenen H.Ü. Çocuk Gelişimi Lisans programının uygulandığı ilk dönemden itibaren farklı dönemlerde ders sorumluları ve öğrencilerden alınan geri bildirimlerle program ile ilgili gerekli güncelleme çalışmaları devam etmiş, 2015 Nisan ayında program 2015-2016 yılı Güz döneminde uygulanan son şeklini almıştır. 


\section{Kaynakça}

Doğan, A. ve Baykoç, N. (2015). Türkiye'de Bulunan Üniversitelerin Lisans Programlarının Çocuk Gelişimi Açısından İncelenmesi. Hacettepe University Faculty of Health Sciences Journal, 1(2), 425-432.

Hacettepe Üniversitesi Çocuk Gelişimi Bölümü (2015). Tarihçe. 12.06.2012 tarihinde http://www.cge.hacettepe.edu.tr/tarihce.shtml adresinden erişildi.

Hacettepe Üniversitesi (2012). 01.08.12 Üniversite Senatosu Karar1. 22.08.2012 tarihinde http://www.hacettepe.edu.tr/duyuru/snykkararlari/1216,skarari010812.pdf adresinden erişildi.

Hacettepe Üniversitesi (2015a). Bologna Şalışmaları. http://www.hubologna.hacettepe.edu.tr/ adresinden 03.07.2015 tarihinde erişildi.

Hacettepe Üniversitesi (2015b). Ders Kataloğu/Ders Bilgi Paketi, Çocuk Gelişimi Programı. 03.07.2015 tarihinde http://akts.hacettepe.edu.tr/program_detay.php?birim_ref=AKDBRM_000000000000 0000000000219\&birim_kod=366\&prg_oid=PRGRAM_00000000000000000000000 $31 \&$ prg_kod=366\&programduzey=2\&submenuheader=2_adresinden erişildi.

Hacettepe Üniversitesi (2015c). H.Ü. Program ve Ders Bilgi Paketi Hazırlama Belgeleri (Seçmeli Dersler - En az \%25). 15.07.2015 tarihinde http://www.hubologna.hacettepe.edu.tr/yardimci_belgeler.shtml ve www.hubologna.hacettepe.edu.tr/SecmeliDerslerEna25.pdf adresinden erişildi.

Yükseköğretim Kurulu (YÖK) (2015a). Bologna Süreci Nedir?. 12.06.2012 tarihinde http://www.yok.gov.tr/web/uluslararasi-iliskiler/bologna-sureci-nedir adresinden erişildi.

Yükseköğretim Kurulu (YÖK) (2015b). Yükseköğretim Yeterlilikler Çerçevesi. 10.09.2015 tarihinde http://tyyc.yok.gov.tr/ adresinden erişildi.

Yükseköğretim Kurulu (YÖK) (2015c). 66 Soruda Bologna Süreci Uygulamaları. 10.09.2015 tarihinde http://www.yok.gov.tr/web/uluslararasi-iliskiler/42 adresinden erişildi. 